\title{
Perceived Effectiveness of Parent Representation Social Workers by Legal Professionals Involved with Indigent Defendants
}

\author{
Jeremiah W. Jaggers \\ Aurene Wilford \\ Ileana Anderson \\ Joanna Bettmann
}

\begin{abstract}
The total number of children in the U.S. foster care system exceeds 428,000. Previous research indicates that when social workers and legal professionals work together, children and their families benefit significantly. Parents who effectively engage in the child welfare system are more likely to benefit from services and reunify with their children. The present study employed a phenomenological approach to explore how a parent representation pilot, which paired social workers with public defenders to better represent the needs of families in the child welfare system, was experienced by legal professionals. Judges and family court attorneys $(n=9)$ found the program to be helpful in reunifying families. Public defenders were able to leverage the social worker's skills and experience to facilitate more positive outcomes, while reducing case burden. Challenges were also identified and included a lack of interdisciplinary training, potential overlap in ethical responsibilities, and role confusion. Structured intervention programs that encourage collaboration between social workers and legal professionals may improve case outcomes for indigent families involved in the child welfare system. It is advised that social work undertake a formal multidisciplinary approach in support of public defenders, which may serve to encourage positive case outcomes.
\end{abstract}

Keywords: Child welfare; parent representation; social work; indigent defendants; foster care

The total number of children under the age of 18 in the U.S. foster care system exceeds 428,000 (Annie E. Casey Foundation, Kids Count Data Center, 2019). National data indicates there were 4.1 million reports of child maltreatment in 2017 involving 7.5 million children; of those, 2.3 million reports had sufficient evidence and needed further investigation (U.S. Department of Health and Human Services, 2017). Such cases entail the whole family becoming involved in social services and the child welfare system. In an effort to reduce the number of youth in out-of-home placements, states like Utah have employed innovative strategies like the Parent Representation Program (PRP) pilot, which partners social workers with legal professionals (e.g., prosecuting attorneys, judges) in the child welfare system. The collaboration between the two professional fields is considered essential to successful outcomes for families (Buchanan \& Orme, 2018; Carnochan et al., 2007; Han et al., 2007; Pott, 2017). Previous research indicates that when social workers and legal professionals work together, children and their families benefit significantly (Pott, 2017). The improved outcomes may be due, in part, to social workers' specific skill set (Carnochan et al., 2007; Geurin et al., 2013; Han et al., 2007; Pott, 2017). Rather than focusing on legal processes, social workers focus on helping each child to achieve the best

Jeremiah W. Jaggers, PhD, MSW, Assistant Professor, Aurene Wilford, Research Analyst, Ileana Anderson, student, and Jaonna Bettman PhD, LCSW Professor, College of Social Work The University of Utah, Salt Lake City, UT. 
possible outcome (Geurin et al., 2013; Pott, 2017). It is vital for parents to have legal representation and guidance in court hearings as they often do not have a comprehensive understanding of the juvenile dependency system. Parents frequently face informational and cultural barriers, which may contribute to parents feeling alienated and disempowered in the legal process (Barsky, 1996). Without proper guidance, parents cannot best advocate for themselves in court proceedings (Wood et al., 2016). Social workers working alongside parents can help them bridge this gap and navigate the complicated court system.

\section{Literature Review}

Child welfare case outcomes have been shown to improve when a multidisciplinary team (MDT) is involved in the case (Bracewell, 2018; Pott, 2017). Although the team members included in each MDT vary, the team typically includes a social worker as well as a legal representative who collaborate on each child welfare case (Bracewell, 2018; Pott, 2017). Studies of MDTs found that when social workers and legal professionals collaborate as a team, the likelihood of family reunification and case resolution increases, while the likelihood of prosecution and out-of-home placements decreases (Bracewell, 2018; Courtney \& Hook, 2011). When there is a strong relationship between professionals on the MDT, children are more likely to be placed with relatives when they must be removed from the home. Several studies demonstrate that children who remain in kinship care placements have lower incidents of behavioral issues compared to children who enter the foster care system (e.g., Rubin et al., 2008; Ryan et al., 2010).

Parents who effectively engage in the child welfare system are more likely to benefit from services and reunify with their children. Hence, the Utah Indigent Defense Commission (IDC) PRP pilot was developed with three main goals:

1. To increase the capacity and efficiency of parental defense attorneys by including social workers on child welfare cases,

2. To achieve better outcomes by connecting court-involved children and their families to services and treatments, and

3. To achieve faster case resolutions and reduce the need for attorney continuances.

A pilot study conducted in Washington found that when indigent parents received enhanced parental representation, the rate of family reunification increased significantly to $68 \%$ (Courtney \& Hook, 2012). The same study also found that PRP pilot implementation resulted in an expedited judicial process regarding permanency placements for children in state care. In cases where family reunification was not possible, the PRP social worker's involvement increased the likelihood that the parents would agree to an out-of-home placement more quickly.

Although the literature suggests that when social workers and legal professionals collaborate child welfare cases have more favorable outcomes, there is a well-documented history of conflict and strained relationships between legal professionals and social workers within the child welfare system (Buchanan \& Orme, 2018; Carnochan et al., 2007; Courtney \& Hook, 2012; Geurin et al., 2013; Han et al., 2007; Pott, 2017). Although many 
studies document the existence of conflict between the two professional fields, to date, there have only been a few studies which examined this conflict's origins (Han et al., 2007). Several factors contribute to the conflict and poor relationships between social workers and legal professionals, including cultural differences between the two professions, low pay and professional status in both professions, and lack of interdisciplinary training and role definition (Carnochan et al., 2007; Han et al., 2007; Johnson \& Cahn, 1995; Pott, 2017). These factors can lead to a lack of respect and trust between the two professional groups, as well as poor communication and information flow (Carnochan et al., 2007; Han et al., 2007).

\section{Cultural Differences}

Cultural differences between the two professional fields can lead to strained relationships between legal professionals and social workers (Carnochan et al., 2007; Han et al., 2007; Pott, 2017; Steen, 2020). The cultural differences originate from a difference in perspectives, professional expectations, and mandates. While social workers typically emphasize a collaborative approach, the legal profession exists in an inherently adversarial setting (Carnochan et al., 2007; Han et al., 2007). Social workers view clients from an ecological perspective, viewing each client within their particular social, political, and cultural contexts and systems. Systems theory informs this social work perspective, viewing clients' behaviors as embedded within their contexts and impacted by multiple systems (Greene, 2017). By contrast, legal professionals tend to focus on clients' individual rights and view the actions of an individual apart from their environment (Carnochan et al., 2007).

According to the American Bar Association's Model Rules of Professional Conduct, lawyers are responsible for upholding the quality of justice (American Bar Association [ABA], Center for Professional Responsibility, 2019). Legal professionals' conduct must conform to the law and demonstrate respect for the legal system. As the legal representative, the lawyer is expected to be competent, timely, and thorough. Lawyers are expected to improve the law as well as improve access to the legal system for all citizens. Additionally, lawyers must adhere to the profession's ideals of public service and the promotion of justice. Legal professionals are relatively autonomous, and thus have the responsibility of self-regulation and self-governance in the public interest (ABA, Center for Professional Responsibility, 2019).

The social work profession similarly has a code of professional conduct to which all social workers are expected to adhere (National Association of Social Workers [NASW], 2017, preamble). However, the primary mission of the social work profession is to promote the well-being of all people, particularly the most vulnerable populations. Social workers are expected to promote social justice and social change. The NASW Code of Ethics requires social workers in the child welfare system to understand the legal profession (Carnochan et al., 2007). According to the NASW Code of Ethics, social workers are expected to practice with competence and be knowledgeable in their area of focus (NASW, 2017). Although legal standards do not require lawyers to have familiarity with the social work perspective, the ABA's model rules similarly promote competence (ABA, Center for 
Professional Responsibility, 2019; Carnochan et al., 2007). Lawyers who work with child abuse victims must consider the emotional and physical factors that contribute to each case, even though such factors may not necessarily align with broader legal culture and education.

\section{Pay and Professional Status}

Family court is often perceived as a low-status setting in the legal system (Carnochan et al., 2007; Han et al., 2007). Lawyers and judges in family court cycle through the court quickly; this pattern is similar to the social work profession where there is also a high turnover rate, especially among child welfare workers (Carnochan et al., 2007; Han et al., 2007; Lizano \& Mor Barak, 2015; Travis et al., 2016; Willis et al., 2016). An exploratory study found that the high turnover of legal professionals and social workers is a strong predictor of the effectiveness of inter-professional communication and collaboration (Han et al., 2007). When communication is interrupted, child welfare professionals perceive cases to be more difficult. The high turnover rates of social workers and legal professionals in the child welfare system makes it challenging for social workers and legal professionals to develop strong relationships, often resulting in overrepresentation of inexperienced staff within the child welfare system (Carnochan et al., 2007; Han et al., 2007).

There is a substantial lack of resources for both public defenders and social workers working in the child welfare system. Social workers in the child welfare system and public defenders are overburdened and underpaid, leading to the perception that they are at the bottom of the court hierarchy (Boyas \& Wind, 2010; Carnochan et al., 2007; Depanfilis \& Zlotnik, 2008; Han et al., 2007; Lizano \& Mor Barak, 2015; Porter, 2017; Travis et al., 2016).

\section{Lack of Interdisciplinary Training and Role Definition}

The lack of interdisciplinary training is another factor contributing to the conflict between legal professionals and social workers (Carnochan et al., 2007; Han et al., 2007; Johnson \& Cahn, 1995). There is a substantial lack of understanding of the other profession's role in the child welfare system (Carnochan et al., 2007; Han et al., 2007; Johnson \& Cahn, 1995). Lawyers surveyed in several studies report that social workers would benefit from more training on the adversarial process, including gaining a better understanding of legal definitions and the legal process (Carnochan et al., 2007; Johnson \& Cahn, 1995). Similarly, social workers surveyed recommended that legal professionals would benefit from more training on social work values and principles (Carnochan et al., 2007; Johnson \& Cahn, 1995). One study found that attorneys want social workers to be more objective and that social workers want attorneys to be less adversarial and allow more time for counseling (Carnochan et al., 2007). Notably, research shows that when social workers and legal professionals receive interdisciplinary training, the friction between the two professions decreases (Bracewell, 2018).

The existing research suggests that inter-professional collaboration between legal professionals and social workers correlates to positive case outcomes in the child welfare 
system (Bracewell, 2018; Carnochan et al., 2007; Courtney \& Hook, 2012; Geurin et al., 2013; Han et al., 2007; Pott, 2017). Thus, the present study sought to explore how a program which paired social workers with public defenders to better represent the needs of families in the child welfare system was perceived by legal professionals. Since these types of programs are relatively new, there is a dearth of research on this topic, especially as it relates to multidisciplinary collaboration.

\section{Method}

\section{Setting}

The primary aim of this study was to evaluate legal professionals' (judges and attorneys) perceived effectiveness of the PRP pilot and to inform future expansion of the program, including additional needs related to training and policy. A process evaluation was conducted to ascertain how the social worker was utilized, what role they took in court proceedings, and to explore the perceived efficacy of having social workers collaborate with public defenders who represent parents in child welfare cases. For simplicity, we refer to the "social worker" as the individual working with the public defender, while "child welfare worker" refers to state employees charged with overseeing the safety of children who are involved with the child welfare system. The Utah Indigent Defense Commission (IDC) was established in 2016 to provide oversight and direction to the state's public defense agencies. One of the newly created agency's initiatives is to enhance the representation of indigent parents alleged to have committed abuse or neglect (Utah IDC Office, 2017). To this end, the PRP pilot paired social workers with public defenders to better represent parents and enhance services already provided by the Utah Division of Child \& Family Services (DCFS), the state's child welfare agency.

\section{Ethics}

Appropriate materials were submitted to the University of Utah Institutional Review Board. A waiver was provided by the overseeing committee since the research was considered program evaluation.

\section{Sampling Procedures and Justification}

Recruitment occurred through collaboration with court administration. Study information, including informational flyers were provided to the court administrator and the director of the public defenders' office. Information was then disseminated to potential participants, which included public defenders, attorneys general, and judges. Interested participants notified the court administrator, the public defender's office, or members of the research team. As part of the PRP pilot evaluation, nine individual interviews were conducted. Interviews were conducted with all juvenile court judges $(\mathrm{n}=3)$, all assistant attorneys general (AAG; $\mathrm{n}=3$ ), and approximately three-quarters of public defenders $(\mathrm{n}=$ 3 ) in the region. Given the limited sampling frame and the potential threats to anonymity, additional information on the participants has been excluded. 
The final sample size was adequate for addressing the study's aim. Several researchers have suggested that fewer than 10 participants is necessary when conducting qualitative inquiry (Creswell, 1998; Moser \& Korstjens, 2018). Others have argued that saturation, not specific a priori recruitment goals, should be used to determine a final posterior sample size (Vasileiou et al., 2018). Saturation is defined as the point at which the data no longer offer any new or related information (Dworkin, 2012). Simply put, "when gathering fresh data no longer sparks new theoretical insights, nor reveals new properties of your core theoretical categories" you have reached saturation (Charmaz, 2006, p. 113). While endorsing this approach, Smith and Osborne (2003) emphasize that, in cases where the topic being researched is limited, such as pilot studies, sampling guidelines may not be applicable (c.f. Smith et al., 2009). Since almost all legal professionals involved in indigent cases within this region were interviewed, saturation was achieved.

\section{Design and Analytic Approach}

After consultation with IDC personnel, the research team determined that a qualitative descriptive approach was most appropriate. Using a qualitative approach and through semistructured interviews, the researchers aimed to understand individuals' perceptions of the PRP pilot. This was an iterative process where codes and themes were identified, across all interviews, using thematic analysis (Braun \& Clarke, 2006). This process required familiarization with the data and listing peoples' ideas, beliefs, or experiences as codes. Further, sorting the data and organizing the data into themes and sub-themes, then consensus coding with other analysts occurred.

Semi-structured interviews were used to collect data from individual participants. This afforded researchers the opportunity to focus on collecting data about specific topics, while permitting the flexibility to explore other relevant areas that arose during the interview. A priori topics of interest included in the interview were questions of process (e.g., "How are clients referred?"; "What information is shared with the DCFS case worker?"), legal ethics, and multi-disciplinary collaboration. The establishment of rapport and empathy is essential to gaining depth of information, particularly when investigating issues where the participant has a strong personal stake (Gorden, 1969; Measor, 1985; Plummer, 1983). Thus, interviews began with a brief discussion about the participant's role in child welfare cases and their specific responsibilities. Participants were then asked about their involvement with the PRP pilot, specifically as it pertained to involvement with the PRP social worker.

Each individual interview was recorded and transcribed using Dragon Speech Recognition Software v15 (Nuance, n.d.). Researchers then manually reviewed each document to correct errors in transcription, and when necessary, to highlight areas emphasized by the participant. Then, researchers coded each transcript independently. Specifically, researchers focused on identifying themes relevant to each individual's experience with the PRP pilot. After individual coding, research staff met and engaged in a consensus coding process. The purpose of the consensus coding was twofold. First, it was necessary to identify areas of overlap. Second, the researchers engaged in a decisionmaking process based upon their areas of methodological and substantive expertise (c.f. 
Elliott, 2018). Subsequent to this process, the researchers finalized codes for each constituent group.

Data were triangulated using two approaches: source triangulation and analyst triangulation (Denzin, 1978; Patton, 1999). First, a comparison was made among people with potentially differing views of the program, namely judges, assistant attorneys general, and public defenders. Each group was found to have a unique perspective on the program, with limited convergence. Excessive convergence is a limitation to qualitative research trustworthiness (Heale \& Forbes, 2013). In this instance, the limited convergence was deemed to be appropriate since all three groups work in a similar environment (the court system) and were trained in an identical fashion (all were lawyers). Second, analyst triangulation was used as part of the consensus coding process. Analyst triangulation entails using multiple analysts to review the findings of others involved in coding the raw data (Patton, 1999). In the current study, three analysts were responsible for coding the data individually and independently. During the consensus process, each analyst was given the opportunity to review and critique the results of other analysts. The consensus process yielded a set of structured codes that originated from the repeated individual codes provided by all three analysts.

\section{Results}

For the PRP pilot, nine legal professionals were recruited; interviews were conducted with juvenile court judges $(\mathrm{n}=3)$, assistant attorneys general (AAG; $\mathrm{n}=3)$, and public defenders $(n=3)$. It should be noted that not all sub-themes applied to each group equally. We have contextualized the findings based not only on the program, but how each group viewed the PRP pilot to emphasize individual and collective experience. What follows is a description of the findings, with sample quotes provided. In the following sample quotes, the social worker's name has been removed and replaced with "[the social worker]" where necessary.

\section{Expertise, the Court Process, and Contextualization}

Judges expressed confidence in the social worker's abilities to represent the parents. This was, in part, due to the social worker's long-time exposure and experience with the child welfare system. One judge stated:

...I have a lot of trust in her because I know her work is done well and I think she has the ability to work well with clients to provide them the help they need to better understand the process.

Judges also recognized the social worker's role in advocating for the parents and in guiding them through the court process. One judge expressed concern about expanding the program, saying this social worker had "unique skills, and may be extraordinary among social workers." In addition, the judges perceived the social worker to have a positive impact on case outcomes, with one judge stating: 
...so I think the cases she is assigned to, the parents are more engaged in the services and there are more positive outcomes.

A second judge echoed this by saying:

[the social worker] provides another piece of information. The more information I have, the better decisions that I make, so anytime I have a social worker that is able to provide additional information, it's going to have an impact on my decisions.

In general, the judges saw the social worker as having a positive impact on case outcomes. The judges reported that the social worker was able to provide additional context and support to the parents, which was seen as a critical part of their role in the process.

\section{Role Confusion and Conflict}

This section includes information provided by the assistant attorneys general (AAGs) when asked about the PRP pilot. The court system has a well-established hierarchy that has existed for generations. Inserting a social worker into the naturally adversarial environment common in the court system resulted in a tension that did not exist prior to the PRP pilot. That tension was obvious in the interviews, as AAGs often expressed frustration around the social worker's role in the process. One attorney said:

The challenge for me is I don't know the exact outline of what that particular role [the social worker's role], how it overlaps with the DCFS [The Division of Child \& Family Services] case worker, what [social workers] can and cannot do. So it was never explained to me.

In addition, AAGs expressed confusion about attorney-client privilege and the social worker's ethical obligations. Clients can share information with their attorney, but does the confidentiality associated with those exchanges extend to the social worker who must follow state laws and NASW ethical guidelines? One AAG summarized the concern by saying:

I think that the public defender would not want [the social worker] to be identified as a paralegal who is assisting in the legal process. They might not want her to be identified as a therapist because there are some protections for therapeutic roles...

Still, they saw the social worker as having a significant influence on case outcomes. One AAG said:

[the social worker] does a fantastic job of assisting parents through the system... but there is often an oppositional position between the state and the parents we are trying to help.

In speaking of the social worker as an advocate, the AAG continued by saying:

We have some parents [pause] who need extra explanation, or they are not very literate, and having someone else there to assist them can be helpful-giving extra guidance to the parent. 
Overall, the AAGs felt the social worker was helpful to parents, but were uncertain about the social worker's role in the legal system's ethical and practical infrastructure.

\section{Social Worker Utility}

This section includes information provided by the public defenders (PDs) who work directly with the social worker in representing the interests of the parents. Most of those interviewed had never worked directly with a social worker before. In fact, many had only engaged with DCFS case managers within the courtroom. Thus, the utility of the social worker was a major point of discussion. In an excited tone, one PD summed up the social worker's importance by saying:

If we had the resources I would recommend a social worker on every case. [The social worker] is so helpful. First of all, [the social worker] helps them [clients] understand the process. Second of all, [the social worker] helps them understand the [DCFS] case worker and her particular case. This is what we need to focus on. 'Here's what the caseworkers looking at. Here's what you need to do based on the adjudication you know, based on these services you have gotta focus on right?' And finally she's just a person who is available more often, I hate to say, than the [DCFS] attorney. She is someone you can always call, you know. She can talk to me, the attorney, and be liaison between all that, and, you know I do not know what I would've done without her in several cases now.

Another PD echoed this sentiment by saying:

I would say it is her more frequent visits with the clients than the attorneys have... she gets to know them better and she can relay pertinent information to the attorneys and they can deal with it on the legal side.

One point raised by the PDs was the social worker's role in reviewing cases and preparing court reports, which substantially relieved part of the PDs work in any given case. Enthusiastically, one PD said:

[The social worker] is a documenter, she is able to say 'hey you know what, yes, I was there when your attorney told you this, that, that and I heard it, and I know it, and I told you the same things' with those clients, I'm so glad she's involved with those cases. She is the third person who documents everything.

While there was some concern that the social worker is another moving part of an already complicated, adversarial system, they were more often regarded as playing an integral and positive role in helping families navigate the court process. The PDs expressed admiration and support for the social worker's role, even suggesting that the program be expanded into additional regions within the state. The social worker was able to provide in-depth services that the PDs did not have the time to provide themselves. The PDs reported that they relied on social workers to connect with families on a regular basis, and to provide any additional information that they needed to know. 


\section{Discussion}

The present study aimed to evaluate how legal professionals perceived the effectiveness of the PRP pilot to inform future expansion of the program. The PRP pilot paired social workers with public defenders. Any mention of social workers reflects those social workers who collaborated with legal professionals. This study focused on how legal professionals perceived the social workers' involvement in child welfare cases. Overall, results demonstrate that legal professionals perceived that social workers positively influenced case outcomes.

Family court judges observed that cases with an assigned social worker had more positive outcomes compared to cases without an assigned social worker. This finding was echoed by one judge who indicated that social workers were able to provide additional information relevant to the case, further enhancing their decision-making capacity. Judges highlighted trust as a major component of social workers' contributions. On multiple occasions, the judges reported being able to trust the PRP social workers due to their skills and expertise. However, the judges also expressed hesitation about the expansion of the PRP pilot, since other judges may have to rely on less experienced social workers.

Public defenders similarly expressed support for the social worker's role in cases and suggested that the program be expanded into additional regions within the state. The PDs also suggested that the social worker's assistance in reviewing cases and preparing court reports significantly lightened their workload. These findings build upon existing studies (Bracewell, 2018; Carnochan et al., 2007; Geurin et al., 2013; Han et al., 2007; Pott, 2017), which found that collaboration between legal professionals and social workers correlates with positive outcomes in child welfare cases.

The AAGs also cited social workers as helpful and having a significant influence on child welfare case outcomes. The AAGs, however, were concerned with role confusion between legal professionals and social workers. They expressed confusion about attorneyclient privilege and the social worker's ethical obligations regarding confidentiality. Specifically, the PDs' ability to withhold privileged information is not shared by social workers who must report suspicions about child maltreatment. This finding is consistent with previous research that role confusion and a lack of understanding of the other profession's role in the system was an important issue in professional collaboration (Carnochan et al., 2007; Han et al., 2007; Johnson \& Cahn, 1995).

The AAGs in this study perceived tension between social workers and PDs which initially arose when social workers joined the public defense team. This finding is supported by previous studies that point to professional tension attributable to the court's hierarchy and adversarial environment (Carnochan et al., 2007; Lizano \& Mor Barak, 2015; Travis et al., 2016). PDs expressed a great deal of gratitude for the social workers' support. This finding may indicate that, while there was strong collaboration between PDs and social workers, tension and conflict extended into the courtroom. A lack of interdisciplinary training may contribute to strained relationships. Notably, social workers often frame client behaviors using the lens of systems theory (Greene, 2017), while legal professionals rely on the framework of the law. These diverse theoretical orientations, as 
well as differences in professional training and orientation, may account for some of the tension between workers from these two professions. Therefore, social workers involved in the child welfare system would likely benefit from additional legal training (Bracewell, 2018; Carnochan et al., 2007; Han et al., 2007; Johnson \& Cahn, 1995), and legal professionals may benefit from training on social workers' specific roles, theoretical orientation, and obligations.

Notably, the present study did not find a perception of cultural differences between the two professional groups as a cause for tension in those relationships. This finding differs from other research (Carnochan et al., 2007; Han et al., 2007; Pott, 2017) which found cultural differences between the two professional groups can lead to strained relationships. It is possible that the nature of the child welfare cases may be a consideration here. Both social workers and public defenders serve to support individuals in poverty. In this specific instance, those impoverished individuals are facing significant legal challenges. Incorporation of a social worker into the public defense team may serve to enhance the public defender's effectiveness, thus mitigating cultural differences.

The present study bolsters the argument for further integration of public defense social workers in child welfare cases (Bracewell, 2018; Carnochan et al., 2007; Geurin et al., 2013; Han et al., 2007; Pott, 2017). This multi-disciplinary team approach appears to produce more positive case outcomes. Additional research is needed to understand the child welfare outcomes of the PRP pilot. Collaboration between social workers and legal professionals is necessary for the child welfare system to function effectively. Likewise, improved inter-professional collaboration is essential to the child welfare system's success. The present study similarly found that collaboration between social workers and legal professionals appears to improve child welfare case outcomes and thus should be expanded.

\section{Limitations}

The present study carries several important limitations. The small sample size for the study poses one limitation. Thus, the results should not be generalized to all populations. Additionally, this study was conducted in one urban area in a large Western state; the interpretation of the data should not be generalized across all states, or across regions within the state. The present study should be replicated in a range of states with different demographics to identify region-specific issues. In addition, it is important determine the efficacy of the PRP pilot. The present study focused on process and perception of efficacy, but future quantitative approaches are advisable. Future research is also needed to determine the specific training needs for social workers in these roles.

\section{Implications for Practice}

This study supports the notion that policy changes, such as requirements for MDTs to include a parent social worker, and multi-disciplinary training can have a significant positive impact on the child welfare system. Collaboration between social workers and legal professionals is linked to positive case outcomes. The social workers' assistance with 
the PDs' workload may be one contributing factor; overwhelmed PDs may have more time to dedicate to each case when they collaborate closely with social workers. Attention should be given to the divergent responsibilities and ethics of each profession. Social workers involved in the child welfare system should receive legal training so they are better prepared to support clients through the legal process. Similarly, legal professionals involved in child welfare cases could benefit by receiving training on social work principles and ethics, so they are likewise better prepared to support the clients in cases with embedded social workers.

The social work profession's focus on liberating people in poverty from social programs and policies that have a disparate, negative impact on them is a seminal component of social work practice and aligns well with the role of PDs. The public defender system is designed to provide legal representation to individuals who cannot afford an attorney-most often those clients live in poverty (c.f. Gideon v. Wainwright, 1963). Legal representation of impoverished individuals and families may not be as effective given the extraordinary case burdens of PDs. Through collaboration with social workers, parental representation could be more effective, reduce case duration, and improve child welfare case outcomes.

Expansion of the PRP pilot and other similar collaborative programs would likely result in a significant structural shift. Historically, the child welfare system has not appointed non-agency social workers to work directly with individuals in collaboration with assigned legal representatives (Pott, 2017). Child welfare workers are almost always the only individual responsible for guiding parents through the court process. A focused effort on expanding PRPs is likely to provide additional support to parents who may not trust or want to work with child welfare workers in what is frequently an adversarial relationship (Pinkney, 2013). Such structural changes will not arise in a progressive and natural fashion. Social work's mission can extend into the courtroom by incorporating multi-disciplinary training. Such trainings could enhance the partnership between lawyers and social workers. Similarly, social workers should advocate for policy change such as additional funding to hire and train social workers to work alongside public defenders. Such funding could expand available social work resources to parents and courts, thereby increasing the odds of successful family reunification. Incorporating parent representation social workers in all indigent defense cases would likely increase the opportunity to enhance child well-being and family reunification.

\section{References}

American Bar Association, Center for Professional Responsibility. (2019). Model rules of professional conduct: Preamble \& scope. https://www.americanbar.org/groups/ professional_responsibility/publications/model_rules of professional_conduct/mode 1 rules of professional_conduct preamble_scope/

Annie E. Casey Foundation. (2019). Kids count data book: State trends in child wellbeing. Annie E. Casey Foundation. https://www.aecf.org/m/resourcedoc/aecf2019kidscountdatabook-2019.pdf 
Barsky, A. E. (1996). Mediation and empowerment in child protection cases. Mediation Quarterly, 14(2), 111-134. https://doi.org/10.1002/crq.3900140204

Boyas, J., \& Wind, L. (2010). Employment-based social capital, job stress, and employee burnout: A public child welfare employee structural model. Children and Youth Services Review, 32(3), 380-388. https://doi.org/10.1016/j.childyouth.2009.10.009

Bracewell, T. E. (2018). Multidisciplinary team involvement and prosecutorial decisions in child sexual abuse cases. Child \& Adolescent Social Work Journal, 35(6), 567576. https://doi.org/10.1007/s10560-018-0557-1

Braun, V., \& Clarke, V. (2006). Using thematic analysis in psychology. Qualitative Research Psychology, 3, 77-101. https://doi.org/10.1191/1478088706qp063oa

Buchanan, S., \& Orme, J. (2019). Impact of social work practice in public defense. Journal of Social Service Research, 45(3), 336-347. https://doi.org/10.1080/01488376.2018.1480559

Carnochan, S., Taylor, S., Abramson-Madden, A., Han, M., Rashid, S., Maney, J., Teuwen, S., \& Austin, M. J. (2007). Child welfare and the courts: An exploratory study of the relationship between two complex systems. Journal of Public Child Welfare, 1(1), 117-136. https://doi.org/10.1300/j479v01n01_06

Charmaz, K. (2006). Constructing grounded theory: A practical guide through qualitative analysis. Sage.

Courtney, M. E., \& Hook, J. (2011). Evaluation of the impact of enhanced parental legal representation on the timing of permanency outcomes for children in foster care. Partners for our children, Discussion Paper, 1(1), 1-11. https://doi.org/10.1016/j.childyouth.2012.03.016

Courtney, M., \& Hook, J. (2012). Evaluation of the impact of enhanced parental legal representation on the timing of permanency outcomes for children in foster care. Children and Youth Services Review, 34(7), 1337-1343. https://doi.org/10.1016/j.childyouth.2012.03.016

Creswell, J. W. (1998). Qualitative inquiry and research design: Choosing among five traditions. Sage.

Denzin, N. K. (1978). Sociological methods. McGraw-Hill.

Depanfilis, D., \& Zlotnik, J. (2008). Retention of front-line staff in child welfare: A systematic review of research. Children and Youth Services Review, 30(9), 995-1008. https://doi.org/10.1016/j.childyouth.2007.12.017

Dworkin, S. L. (2012). Sample size policy for qualitative studies using in-depth interviews. Archives of Sexual Behavior, 41, 1319-1320. https://doi.org/10.1007/s10508-012-0016-6

Elliott, V. (2018). Thinking about the coding process in qualitative analysis. Qualitative Report, 23(11), 2850-2861. 
Geurin, L., Otis, M., \& Royse, D. (2013). Increasing alternative sentencing in the juvenile justice system through a partnership between public defenders and social workers. Journal of Forensic Social Work, 3(3), 261-277. https://doi.org/10.1080/1936928x.2013.859026

Gideon v. Wainwright, Volume 372 U.S. 335. (1963). https://www.law.cornell.edu/supremecourt/text/372/335

Gorden, R. L. (1969). Interviewing: Strategy, techniques and tactics. Dorsey Press.

Greene, R. (2017). Human behavior theory and social work practice. Routledge.

Han, M., Carnochan, S., \& Austin, M. J. (2007). The challenges to promoting collaboration between child protection services workers and court professionals: An exploratory study of case records. Journal of Public Child Welfare, 1(3), 115-131. https://doi.org/10.1300/j479v01n03_07

Heale, R., \& Forbes, D. (2013). Understanding triangulation in research. Evidence Based Nursing, 16(4), 98.

Johnson, P., \& Cahn, K. (1995). Improving child welfare practice through improvements in attorney-social worker relationships. Child Welfare, 74(2), 383-394.

Lizano, E., \& Mor Barak, M. (2015). Job burnout and affective wellbeing: A longitudinal study of burnout and job satisfaction among public child welfare workers. Children and Youth Services Review, 55(C), 18-28. https://doi.org/10.1016/j.childyouth.2015.05.005

Measor, L. (1985). Interviewing: A strategy in qualitative research. In R. Burgess (Ed.), Strategies of educational research: Qualitative methods (pp. 55-77). Falmer Press.

Moser, A., \& Korstjens, I. (2018). Series: Practical guidance to qualitative research. Part 3: Sampling, data collection and analysis. European Journal of General Practice, 24(1), 9-18. https://doi.org/10.1080/13814788.2017.1375091

National Association of Social Workers. (2017). Preamble to the code of ethics. Retrieved from https://www.socialworkers.org/About/Ethics/Code-of-Ethics/Codeof-Ethics-English

Nuance [computer software]. (n.d.). Dragon Speech Recognition Version 15. https://www.nuance.com/dragon.html

Patton, M. Q. (1999). Enhancing the quality and credibility of qualitative analysis. HSR: Health Services Research, 34(5), 1189-1208.

Pinkney, S. (2013). Trust relationships between children, social welfare professionals and the organisations of welfare. In H. Warming (Ed.), Participation, citizenship and trust in children's lives. Studies in childhood and youth (pp. 93-113). Palgrave Macmillan. https://doi.org/10.1057/9781137295781_6

Plummer, K. (1983). Documents of life: An introduction to the problems and literature of a humanistic method. Unwin Hyman. 
Porter, D. (2017). Paying for justice: The human cost of public defender fees. American Civil Liberties Union. https://aw.yale.edu/sites/default/files/area/center/liman/ document/pdfees-report.pdf

Pott, R. (2017). Delivering social work services in collaboration with the legal representation for individual clients: An effective, ethical and economical approach to supporting families in child abuse and neglect legal proceedings. Child Abuse \& Neglect, 73, 24-29. https://doi.org/10.1016/j.chiabu.2017.09.011

Rubin, D., Downes, K., O'Reilly, A., Mekonnen, R., Luan, X., \& Localio, R. (2008). Impact of kinship care on behavioral well-being for children in out-of-home care. Archives of Pediatrics \& Adolescent Medicine, 162(6), 550-556. https://doi.org/10.1001/archpedi.162.6.550

Ryan, J., Hong, J., Herz, D., \& Hernandez, P. (2010). Kinship foster care and the risk of juvenile delinquency. Children and Youth Services Review, 32(12), 1823-1830. https://doi.org/10.1016/j.childyouth.2010.08.003

Smith, J. A., \& Osborn, M. (2003). Interpretative Phenomenological Analysis. In J. A. Smith (Ed.), Qualitative psychology: A practical guide to research methods (p. 5180). Sage.

Smith, J. A., Flowers, P., \& Larkin, M. (2009). Interpretive phenomenological analysis: Theory, method and research. Sage.

Steen, J. (2020). The role of voice suppression in case managers' job satisfaction and retention. Advances in Social Work, 20(1), 82-94. https://doi.org/10.18060/23707

Travis, D., Lizano, E., \& Mor Barak, M. (2016). 'I'm so stressed!': A longitudinal model of stress, burnout and engagement among social workers in child welfare settings. British Journal of Social Work, 46(4), 1076-1095. https://doi.org/10.1093/bjsw/bct205

Utah Indigent Defense Commission. (2017). Utah indigent defense commission: Judiciary interim committee. The sixth amendment. https://le.utah.gov/interim/2017/pdf/00002494.pdf

U.S. Department of Health and Human Services. (2017). Child welfare outcomes report date. https://cwoutcomes.acf.hhs.gov/cwodatasite/threeOne/index

Vasileiou, K., Barnett, J., Thorpe, S., \& Young, T. (2018). Characterising and justifying sample size sufficiency in interview-based studies: Systematic analysis of qualitative health research over a 15-year period. BMC Medical Research Methodology, 18(148) 1-18. https://doi.org/10.1186/s12874-018-0594-7

Willis, N., Chavkin, N., \& Leung, P. (2016). Finding "Health" and "Meaning" in Texassized turnover: Application of seminal management principles for administration and research in U.S. public child welfare agencies. Advances in Social Work, 17(2), 116133. https://doi.org/10.18060/20856 
Wood, S. M., Summers, A., \& Duarte, C. S. (2016). Legal representation in the juvenile dependency system: Travis County, Texas' parent representation pilot project. Family Court Review, 54(2), 277-287. https://doi.org/10.1111/fcre.12218

Author note: Address correspondence to Jeremiah W. Jaggers, College of Social Work, University of Utah, Salt Lake City, UT 84112. Email: jeremiah.jaggers@utah.edu 